\title{
Multiple amino acid substitutions in lanosterol $14 \alpha$-demethylase contribute to azole resistance in Candida albicans
}

\author{
Bertrand Favre, $\uparrow$ Mark Didmon and Neil S. Ryder \\ Author for correspondence: Neil S. Ryder. Tel: +43 186634 324. Fax: +43186634354. \\ e-mail: neil.ryder@pharma.novartis.com
}

Novartis Research Institute, Brunner Strasse 59, A-1235 Vienna, Austria
Lanosterol 14 $\alpha$-demethylase (14DM) is the target of the azole antifungals, and alteration of the 14DM sequence leading to a decreased affinity of the enzyme for azoles is one of several potential mechanisms for resistance to these drugs in Candida albicans. In order to identify such alterations the authors investigated a collection of $19 \mathrm{C}$. albicans clinical isolates demonstrating either frank resistance (MICs $\geq 32 \mu \mathrm{g} \mathrm{ml}^{-1}$ ) or dose-dependent resistance (MICs 8-16 $\mu \mathrm{g}$ $\mathrm{ml}^{-1}$ ) to fluconazole. In cell-free extracts from four isolates, including the Darlington strain ATCC 64124, sensitivity of sterol biosynthesis to inhibition by fluconazole was greatly reduced, suggesting that alterations in the activity or affinity of the 14DM could contribute to resistance. Cloning and sequencing of the 14DM gene from these isolates revealed 12 different alterations (two to four per isolate) leading to changes in the deduced amino acid sequence. Five of these mutations have not previously been reported. To demonstrate that these alterations could affect fungal susceptibility to azoles, the 14DM genes from one sensitive and three resistant $C$. albicans strains were tagged at the carboxyl terminus with a c-myc epitope and expressed in Saccharomyces cerevisiae under control of the endogenous promoter. Transformants receiving 14DM genes from resistant strains had fluconazole MICs up to 32-fold higher than those of transformants receiving 14DM from a sensitive strain, although Western blot analysis indicated that the level of expressed 14DM was similar in all transformants. Amino acid substitutions in the 14DM gene from the Darlington strain also conferred a strong cross-resistance to ketoconazole. In conclusion, multiple genetic alterations in C. albicans 14DM, including several not previously reported, can affect the affinity of the enzyme for azoles and contribute to resistance of clinical isolates.

Keywords: azoles, fluconazole resistance, Candida albicans, lanosterol $14 \alpha$-demethylase

\section{INTRODUCTION}

Candida albicans, an asexual, diploid and dimorphic fungus, is the most common opportunistic fungal pathogen of humans (Rinaldi, 1993). Immunocompromised patients are particularly susceptible to infection by C. albicans and more than $80 \%$ of AIDS patients suffer from oropharyngeal candidiasis during the course

\footnotetext{
†Present address: Department of Dermatology, Hôpital Cantonal Universitaire de Genève, 24 Rue Micheli-du-Crest, CH-1211 Geneva 14, Switzerland

Abbreviation: 14DM, lanosterol 14 $\alpha$-demethylase.
}

of their illness. The most commonly used antimycotic to prevent or combat mucosal and systemic candidiasis is fluconazole, because of its favourable bioavailability and safety profile (Feczcko, 1992). The primary target of the azole antimycotics is lanosterol $14 \alpha$-demethylase (14DM), a key enzyme in the ergosterol biosynthesis pathway (Hitchcock, 1993; Vanden Bossche \& Koymans, 1998). $14 \mathrm{DM}$ is a $\mathrm{P} 450$ haem thiolate protein which catalyses, in the presence of NADPH reductase, the oxidative removal of the $14 \alpha$-methyl group (C-32) from lanosterol (Aoyama et al., 1989). 14DM is inhibited by azoles in a competitive manner. The imidazole or triazole moiety of azoles replaces water in the sixth coordination position of the haem in the active site, 
while substituent groups interact directly with the protein backbone (Hitchcock, 1993; Hitchcock et al., 1990; Vanden Bossche \& Marichal, 1992; Vanden Bossche \& Koymans, 1998; Yoshida \& Aoyama, 1985).

The prolonged and repeated periods of treatment needed by AIDS patients have led to the increasing occurrence of candidiasis resistant to fluconazole therapy. Drug susceptibility testing of C. albicans isolated from these patients revealed in many cases that the organism had acquired resistance to fluconazole (Denning et al., 1997; Law et al., 1994; Rex et al., 1995; Tumbarello et al., 1996; White et al., 1998). Several mechanisms, independent of 14DM, have been reported which could contribute at least partially to fluconazole resistance in Candida species, including increased ergosterol biosynthesis (Vanden Bossche et al., 1992), a lesion in $\Delta 5,6$ sterol desaturase (Kelly et al., 1997), and lower intracellular accumulation of the drug (Marichal et al., 1995; Parkinson et al., 1995; Sanglard et al., 1995; Vanden Bossche et al., 1992; Venkateswarlu et al., 1996, 1997). This last mechanism seems to be the most common and is associated with the overexpression of two types of multidrug transporters, the ATP-binding cassette (ABC) transporters (Albertson et al., 1996; Miyazaki et al., 1998; Moran et al., 1998; Prasad et al., 1995; Sanglard et al., 1995, 1996, 1997; van Veen \& Konings, 1998; White, 1997a) and the major facilitators (Albertson et al., 1996; Goldway et al., 1995; Moran et al., 1998; Sanglard et al., 1995, 1996; White, 1997a). Recently, additional C. albicans genes able to directly or indirectly confer resistance to fluconazole when expressed in Saccharomyces cerevisiae have been identified (Alarco et al., 1997; Sanglard et al., 1997).

An obvious mechanism for resistance to azoles would be alteration of their primary target, 14DM. Based on indirect biochemical evidence, both overexpression and mutation of $14 \mathrm{DM}$ have been suggested to explain acquired resistance to azoles in several fungi (Ishida et al., 1988; Joseph-Horne et al., 1995; Lamb et al., 1995; Orozco et al., 1998; Vanden Bossche et al., 1990, 1992, 1994; Venkateswarlu et al., 1997; White, $1997 \mathrm{a}, \mathrm{b})$. In S. cerevisiae, overexpression of 14DM encoded by ERG11 leads to resistance to azoles, but the amplitude of resistance is rather weak, not exceeding fivefold (Doignon et al., 1993; Kalb et al., 1986; Kelly et al., 1993). Several studies have supported the concept that azole resistance can be due to mutation(s) in 14DM (Lamb et al., 1997; Loeffler et al., 1997; White, 1997b). Substitution of the highly conserved residue T315A in the C. albicans 14DM gene (CaERG11, also called ERG16 and CYP51A1) conferred a fivefold resistance to azoles when this gene was expressed in $S$. cerevisiae (Lamb et al., 1997). Sequencing of CaERG11 from a number of clinical isolates revealed the existence of numerous amino acid substitutions in the gene amplified from resistant isolates, suggesting a possible link with the resistant phenotype (Loeffler et al., 1997). Lower sensitivity of sterol biosynthesis to fluconazole in cellfree extracts from a fluconazole-resistant C. albicans isolate correlates with the amino acid substitution
R467L in CaERG11 at both loci in the diploid genome resulting from a loss of allelic variation (White, 1997b). Very recently, Sanglard et al. (1998) have formally demonstrated that several mutations in CaERG11 can confer azole resistance upon $S$. cerevisiae. Interestingly, a single point mutation does not seem to drastically affect azole sensitivity of CaERG11 but combinations of point mutations, principally G129A with G464S, Y132H with S405F, or Y132H with G484S, have cooperative effects (Sanglard et al., 1998).

The present study was performed as part of an ongoing project to develop novel approaches to overcoming fungal drug resistance. Using a collection of fluconazoleresistant clinical isolates, we first identified potentially altered 14DM by measuring sensitivity to azole of sterol synthesis in cell-free extracts. Cloning and sequencing of CaERG11 from the four isolates from which cell-free sterol synthesis was insensitive to fluconazole revealed the presence of several amino acid substitutions in each of them. Five of the 12 identified amino acid substitutions have not been previously reported and all their combinations are novel. Finally, we show that expression of altered CaERG11 in S. cerevisiae resulted in increased resistance to fluconazole and, to a variable extent, also to ketoconazole.

\section{METHODS}

Strains. Azole-resistant clinical isolates were from patients who had failed therapy with fluconazole and were obtained from clinical centres in Europe, North America and Australia. The Darlington strain, ATCC 64124, originally isolated from a patient suffering from chronic mucocutaneous candidiasis and treated with ketoconazole (Ryley et al., 1984), was obtained from the American Type Culture Collection. Species were identified using the API 20C test (bioMérieux), as well as CHROMagar (Mast Diagnostica) and Albicans ID agar (bioMérieux). The $S$. cerevisiae strains INVSC2 (MAT $\alpha$ his3-

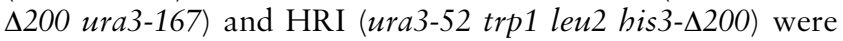
obtained from Invitrogen and Anneliese Karwan (Vienna), respectively.

MIC determinations. Fluconazole, itraconazole and ketoconazole were prepared by Novartis Pharmaceuticals. Drug susceptibility testing of Candida species was performed in a broth macrodilution assay slightly modified from the NCCLS system (Galgiani et al., 1995), as previously described (Ryder et al., 1998). Drugs were prepared according to the recommendations of the NCCLS method. MIC was defined as the lowest drug concentration causing $80 \%$ inhibition of fungal growth. The assay was validated with the standard drugs fluconazole, amphotericin B (Bristol-Myers Squibb) and 5fluorocytosine (Sigma) in three reference strains of C. albicans: ATCC 90028, ATCC 90029 and ATCC 24433 (Galgiani et al., 1995). The reference strains of C. krusei (ATCC 6258) and C. parapsilosis (ATCC 22019) were used to validate the assay with itraconazole and ketoconazole (Rex et al., 1996). To ensure reproducibility, strain ATCC 24433 was run in parallel with each set of assays; MICs with this strain never varied by more than one dilution.

A microdilution assay using a 96-well plate with a flat bottom and low-evaporation lid (Costar) was developed to test drug susceptibility of $S$. cerevisiae. Under the same conditions, the 
micro assay gave similar results to those initially obtained with the macro assay. Briefly, to $200 \mu \mathrm{l}$ per well of a cell suspension at $2.5 \times 10^{3}$ c.f.u. $\mathrm{ml}^{-1}$, prepared in the same medium as for the macro assay but supplemented with $1.8 \%$ glucose (final concn $2 \%$ ) and $0.2 \mathrm{mg}$ adenine $\mathrm{ml}^{-1}$ (as well as $0 \cdot 2 \mathrm{mg}$ uracil $\mathrm{ml}^{-1}$ for untransformed cells), $2 \mu \mathrm{l}$ of a serial twofold dilution of fluconazole or ketoconazole in DMSO was added. The plate was shaken for $10 \mathrm{~min}$ at 900 r.p.m. and incubated for $48 \mathrm{~h}$ at $32{ }^{\circ} \mathrm{C}$ in maximum relative humidity. Growth was monitored spectrophotometrically at $620 \mathrm{~nm}$ with a Digiscan microtitre plate reader (Asys Hitech) after having shaken the plates for $30 \mathrm{~min}$ at 900 r.p.m. MICs were defined as the minimal drug concentration reducing growth by $\geqslant 80 \%$, in comparison with solvent controls.

Sterol biosynthesis assay in whole cells or cell-free extracts. Whole-cell ergosterol biosynthesis was measured by incorporation of $\left[1,2-{ }^{14} \mathrm{C}\right]$ acetate into nonsaponifiable lipids as described previously (Ryder, 1985; Ryder et al., 1984). Sterol synthesis in cell-free extracts, prepared as in Favre \& Ryder (1997b) and Ryder (1987), was assayed in a final volume of $500 \mu \mathrm{l}$, consisting of $50 \mathrm{mM}$ sodium/potassium phosphate $\mathrm{pH} 7 \cdot 4,0.5 \mathrm{mM}$ DTT, $1 \mathrm{mM}$ NAD, $1 \mathrm{mM}$ NADP, $0 \cdot 1 \mathrm{mM}$ FAD, $3 \mathrm{mM}$ glucose 6-phosphate, $5 \mathrm{mM}$ ATP, $3 \mathrm{mM}$ glutathione, $2.7 \mathrm{mM} \mathrm{MnCl}_{2}, 4 \mathrm{mM} \mathrm{MgCl}$ and $0.5 \mu \mathrm{Ci}\left(1.85 \times 10^{4}\right.$ Bq) $(R S)-\left[2-{ }^{14} \mathrm{C}\right]$ mevalonate, supplemented with $1.25 \mathrm{mg}$ protein from cell-free extracts and the appropriate concentration of antimycotic, added from a 50-fold concentrated stock prepared in DMSO. After $2 \mathrm{~h}$ incubation at $30^{\circ} \mathrm{C}$ in a shaking water bath, reactions were terminated by the addition of $1 \mathrm{ml}$ $15 \% \mathrm{KOH}$ in $90 \%$ ethanol. Nonsaponifiable lipids were extracted and analysed by TLC (Ryder, 1985; Ryder et al., 1984); the ${ }^{14}$ C-radioactivity present in each fraction was measured with an Instant Imager (Packard). Reproducibility of extraction was regularly checked by adding 15000 d.p.m. of $\left[1 \alpha, 2 \alpha(\mathrm{n})-{ }^{3} \mathrm{H}\right]$ cholesterol, as internal standard, cutting the region corresponding to 4-desmethyl sterols and measuring the ${ }^{3} \mathrm{H}$-radioactivity by scintillation counting (Favre \& Ryder, 1996). IC $_{50}$ values were calculated from a sterol biosynthesis inhibition curve determined with at least four different concentrations of the antimycotics.

Cloning and sequencing of CaERG11. Genomic DNA from C. albicans was isolated according to Philippsen et al. (1991). PCR amplification of CaERG11 from genomic DNA was performed with the forward primer 5'-CTCGGATCCTATATATATAAGTTTCTTTTCAAGAAGATCATAACTCAAT-3' and the reverse primer 5'-CCGAATTCATCAGAACACTGAATCGAAAGAAAGTTGCCGTTTTA-3', including a BamHI and an EcoRI site, respectively. PCR was conducted using the polymerases mixture Expand High Fidelity (Boehringer Mannheim) and an annealing temperature of $55^{\circ} \mathrm{C}$ under standard conditions. For direct sequencing, the PCR amplicons were purified with the PCR product purification kit from Qiagen. For cloning, PCR products were digested with BamHI and EcoRI and ligated into the vector $\mathrm{pBS}^{+}$(Stratagene). Sequencing on both strands of two independent clones or PCR amplicons was performed with a Li-Cor automatic sequencer, model 4000, using primers labelled with the infrared dye IRD40 (MWG Biotech) and Thermosequenase (Amersham).

Expression of c-myc-tagged CaERG11 in S. cerevisiae. An Ncol site containing the translational initation codon was introduced at the $5^{\prime}$ end, whereas a c-myc tag sequence and an $X b a I$ site were inserted at the $3^{\prime}$ end of CaERG11 ORF by two PCR amplifications from the cloned genes in $\mathrm{pBS}^{+}$, using the forward primer 5'-AACGTGCCATGGCTATTGTTGAAA-
CTGTCATTG-3' and sequentially the following reverse primers: (1) 5'-CTTCAGAAATAAGTTTTTGTTCAAACATACAAGTTTCTCTTTTTTCC-3' and (2) 5'-GGTCTAGATTATTAAAGATCTTCTTCAGAAATAAGTTTTTGTTC-3'. A similar strategy was applied to introduce the same c-myc sequence at the $5^{\prime}$ end of CaERG11 ORF, between the translational initiation codon ATG and the triplet encoding the second amino acid. The promoter of $S$. cerevisiae ERG11 was PCR-amplified from genomic DNA isolated from the strain HRI with the following forward and reverse primers, which contain an XbaI and an NcoI site, respectively: 5'CCTCTAGAGACAATACAACCAACCTTCCTCC-3' and 5'-CTTGGTAGCAGCCATGGTTGTATTACTCGTTTG3 . The identity of the amplified fragment of approximately $1 \mathrm{kbp}$ including the ERG11 promoter (accession no. U10555) was confirmed by restriction analysis and partial sequencing. The terminator of $S$. cerevisiae CYC1 was amplified by PCR from the plasmid pYES2 (Invitrogen) with the forward and reverse primers, which contain an $\mathrm{XbaI}$ and a XboI site, respectively: 5'-ATGCATCTAGAGGGCCGCATC-3' and 5'-CACCTGCTCGAGGGCCGCAAATTAAAGCCTTCGA-3'. Amplified CaERG11 genes, digested with NcoI and $X b a \mathrm{I}$, and the CYC1 terminator, digested with $X b a \mathrm{I}$ and Xhol, were subcloned together into the plasmid Litmus 28 (BioLabs). Finally, the ERG11 promoter, digested with XbaI and NcoI, and the previous insert in Litmus 28, isolated by digesting the plasmid with $\mathrm{NcoI}$ and $\mathrm{XhoI}$, were cloned into the vector pRS416 (Stratagene). For each final construct of cmyc-tagged CaERG11 in pRS416, the ORF was completely sequenced to make sure that no mutation had been introduced by the PCR amplifications and the various cloning steps.

The triplet ${ }^{787} \mathrm{CTG}$ in CaERG11 ORF (encoding Ser in C. albicans: Santos \& Tuite, 1995) was replaced by the triplet TCT with the QuickChange site-directed mutagenesis kit (Stratagene) using the primer 5'-CTTATATGAAAGAAATTAAATCTAGAAGAGAACTGTGTG-3' and its reversed, complementary primer, which contain an XbaI site. To preserve the amino acid substitution E266D in CaERG11 from the strain NFI 2007, the same primers as above, except for the substitution $\mathrm{A}^{32} \rightarrow \mathrm{C}$, were used, whereas the standard primers were applied to suppress the alteration. After site-directed mutagenesis, CaERG11 ORFs were again completely sequenced to confirm the replacement of ${ }^{787} \mathrm{CTG}$ by TCT (identified by restriction analysis with $\mathrm{XbaI}$ ) and to ensure that no other mutations had been introduced.

S. cerevisiae INVSC2 was transformed with pRS416 containing or not containing CaERG11 using the lithium acetate method (Becker \& Guarente, 1991). Two colonies from each transformation were isolated and independently analysed.

Antibodies and Western blotting. Whole-cell extracts were prepared according to Favre \& Ryder (1997a). Cell lysates from $S$. cerevisiae transformants were prepared from cultures grown in conditions as similar as possible to those for MIC determinations (medium, temperature and cell density) in $250 \mathrm{ml}$ Erlenmeyer flasks containing $100 \mathrm{ml}$ medium for $24 \mathrm{~h}$ without agitation, harvested by centrifugation, washed with phosphate-buffered saline and either immediately processed or frozen at $-70{ }^{\circ} \mathrm{C}$. Protein concentration was determined with the Bradford reagent and detergent-compatible (DC) protein assay (Bio-Rad), for samples without and with detergents, respectively. Western blot analysis with the monoclonal anti-c-myc antibodies (clone 9E10, Boehringer Mannheim), $10 \mu \mathrm{g} \mathrm{ml}^{-1}$, was performed as previously described (Favre \& Ryder, 1997a). Membranes were exposed to Hyperfilm ECL (Amersham). 


\section{RESULTS}

\section{Selection of C. albicans isolates with enzymic resistance to fluconazole}

Out of the 23 C. albicans isolates obtained from patients who had failed azole therapy, only 19 demonstrated either dose-dependent or frank resistance to fluconazole in vitro (MIC range 8 to $>128 \mu \mathrm{g} \mathrm{ml}^{-1}$ ), as determined by the NCCLS method (Galgiani et al., 1995; Ghannoum et al., 1996). In order to identify strains which might express altered 14DM genes among these 19 isolates, we measured the sensitivity to fluconazole of the incorporation of $(R S)-\left[2-{ }^{14} \mathrm{C}\right]$ mevalonate into sterols in cellfree extracts. Disruption of the cell membrane should eliminate the effect of multidrug transporters on the sensitivity of sterol synthesis to fluconazole, whereas other mechanisms of resistance, independent of cell integrity, such as overexpression or mutation of 14DM, should still be effective. In four isolates, Darlington

Table 1. Susceptibility to fluconazole (FLU), ketoconazole (KETO) and itraconazole (ITRA) of the four selected azole-resistant $C$. albicans isolates in comparison with that of four sensitive strains

\begin{tabular}{|lccc|}
\hline Strain & \multicolumn{3}{c|}{ MIC $\left(\boldsymbol{\mu \mathrm { g } \mathrm { m } ^ { - 1 } )}\right.$} \\
\cline { 2 - 4 } & FLU & KETO & ITRA \\
\hline Darlington & $>128$ & 32 & $>4$ \\
NFI 2007 & 32 & 1 & $0 \cdot 25$ \\
NFI 2013 & $>128$ & $0 \cdot 5$ & $>4$ \\
NFI 2021 & $>128$ & $0 \cdot 25$ & 1 \\
Normal* & $0 \cdot 25-0 \cdot 5$ & $0 \cdot 06-0 \cdot 12$ & $0 \cdot 02-0 \cdot 12$ \\
\hline
\end{tabular}

"Range of values obtained with the sensitive strains NFI 0124, ATCC 90028, ATCC 90029 and ATCC 24433.
(ATCC 64124), NFI 2007, NFI 2013 and NFI 2021, cellfree sterol synthesis was insensitive to inhibition by fluconazole, with a greater than 50 -fold increase in the $\mathrm{IC}_{50}$ compared to susceptible strains (see below). These four isolates were selected for in-depth susceptibility testing, biochemical characterization of sterol biosynthesis, and molecular analysis of CaERG11.

\section{Biological and biochemical characterization of four selected azole-resistant isolates}

Susceptibility of the four selected fluconazole-resistant strains to several azoles was measured and compared with that of a set of four control strains, known to be susceptible to these drugs (NFI 0124, ATCC 90028, ATCC 90029 and ATCC 24433). Most of the fluconazole-resistant strains showed some degree of crossresistance to ketoconazole (especially, as expected, the Darlington strain) and itraconazole, although to various extents (Table 1 ).

In parallel to MIC determinations, the sensitivity of sterol synthesis to inhibition by fluconazole, ketoconazole and itraconazole was determined both in whole cells and in cell-free extracts. In whole cells, inhibition of $\left[1,2-{ }^{14} \mathrm{C}\right]$ acetate incorporation by the antimycotics correlated with increasing MICs, with a few exceptions which might be due to the different experimental conditions used for each of the two assays. In contrast, sensitivity of sterol synthesis in cell-free extracts to the various antimycotics did not correlate with MICs (Tables 1 and 2). This suggests that at least two distinct mechanisms were responsible for the observed resistance to azoles: one at the enzymic level, mainly affecting fluconazole and sometimes ketoconazole, and a second, which influenced the action of all azoles including itraconazole and was suppressed by disruption of the cell membrane, suggesting the involvement of membrane transporters.

Table 2. Sensitivity of sterol synthesis to inhibition by azoles determined in whole cells and cell-free extracts from the four selected azole-resistant $C$. albicans isolates, in comparison with that of four sensitive strains

\begin{tabular}{|c|c|c|c|c|c|c|}
\hline \multirow[t]{3}{*}{ Strain } & \multicolumn{6}{|c|}{$\mathrm{IC}_{50}(\mu \mathrm{M})^{*}$} \\
\hline & \multicolumn{2}{|c|}{ Fluconazole } & \multicolumn{2}{|c|}{ Ketoconazole } & \multicolumn{2}{|c|}{ Itraconazole } \\
\hline & Cells & Cell-free & Cells & Cell-free & Cells & Cell-free \\
\hline Darlington & $>300$ & $2 \cdot 6$ & $2 \cdot 8$ & 0.067 & $0 \cdot 34$ & $0 \cdot 006$ \\
\hline NFI 2007 & $>100$ & $0 \cdot 8$ & $0 \cdot 1$ & 0.003 & $0 \cdot 31$ & $0 \cdot 001$ \\
\hline NFI 2013 & $>300$ & $0 \cdot 5$ & $3 \cdot 3$ & $0 \cdot 010$ & 0.53 & $0 \cdot 004$ \\
\hline NFI 2021 & $>1000$ & $0 \cdot 9$ & $0 \cdot 2$ & $0 \cdot 029$ & $0 \cdot 14$ & $0 \cdot 010$ \\
\hline Normal† & 3 & 0.007 & $0 \cdot 03$ & $0 \cdot 002$ & 0.03 & 0.002 \\
\hline
\end{tabular}

* The standard deviation, calculated from $\geqslant 2$ independent experiments performed in duplicate, did not exceed $50 \%$ of the mean values.

† Mean of values obtained with the four sensitive strains NFI 0124, ATCC 90028, ATCC 90029 and ATCC 24433. The standard deviation did not exceed $50 \%$ of the mean value. 
Mutations in C. albicans $14 \alpha$-demethylase gene

Table 3. Analysis by TLC of the distribution of incorporated $\left[1,2-{ }^{14} \mathrm{C}\right]$ acetate into squalene and sterols in whole cells of the four selected azole-resistant C. albicans isolates, in comparison with that of four sensitive strains

\begin{tabular}{|c|c|c|c|c|c|c|c|c|}
\hline \multirow[t]{3}{*}{ Strain } & \multicolumn{8}{|c|}{ Incorporation of radioactivity ( $\%$ of total) } \\
\hline & \multicolumn{2}{|c|}{ 4-Desmethyl sterol } & \multicolumn{2}{|c|}{ 4-Methyl sterol } & \multicolumn{2}{|c|}{ Lanosterol } & \multicolumn{2}{|c|}{ Squalene } \\
\hline & Mean & $\mathrm{SD}^{*}$ & Mean & $\mathrm{SD}^{*}$ & Mean & $\mathrm{SD}^{*}$ & Mean & $\mathrm{SD}^{*}$ \\
\hline Darlington & $49 \cdot 7$ & $\pm 9 \cdot 2$ & $4 \cdot 8$ & $\pm 0 \cdot 8$ & $26 \cdot 4$ & $\pm 6 \cdot 9$ & $17 \cdot 0$ & $\pm 4 \cdot 7$ \\
\hline NFI 2007 & $42 \cdot 6$ & $\pm 9 \cdot 8$ & $6 \cdot 2$ & $\pm 1 \cdot 4$ & $26 \cdot 8$ & $\pm 4 \cdot 9$ & $14 \cdot 7$ & $\pm 5 \cdot 0$ \\
\hline NFI 2013 & $30 \cdot 9$ & $\pm 4 \cdot 7$ & $5 \cdot 0$ & \pm 0.6 & $56 \cdot 3$ & $\pm 5 \cdot 0$ & $7 \cdot 8$ & $\pm 3 \cdot 0$ \\
\hline NFI 2021 & $88 \cdot 4$ & $\pm 3 \cdot 5$ & $2 \cdot 8$ & \pm 0.6 & $5 \cdot 3$ & $\pm 1 \cdot 8$ & $3 \cdot 5$ & $\pm 1 \cdot 8$ \\
\hline Normal† & $81 \cdot 5$ & $\pm 4 \cdot 3$ & $4 \cdot 1$ & $\pm 0 \cdot 9$ & $5 \cdot 6$ & $\pm 1 \cdot 5$ & $8 \cdot 2$ & $\pm 4 \cdot 7$ \\
\hline
\end{tabular}

$* n \geqslant 4$.

† Mean of the values obtained with the four sensitive strains NFI 0124 and ATCC 90028, ATCC 90029 and ATCC 24433.

Analysis of the distribution of the radioactivity incorporated from the precursor $\left[1,2-{ }^{14} \mathrm{C}\right]$ acetate into squalene and sterols by TLC revealed that in strains Darlington, NFI 2007 and NFI 2013, a larger proportion of radioactivity was associated with squalene and especially lanosterol in comparison with that from sensitive strains or the fluconazole-resistant strain NFI 2021 (Table 3). Similar results were obtained from the analysis of sterol synthesis in cell-free extracts with $(R S)-\left[2-{ }^{14} \mathrm{C}\right]$ mevalonate as the sterol precursor (data not shown). These results suggest that fluconazole resistance in strains Darlington, NFI 2007 and NFI 2013 is associated with a defective 14DM activity, implying that alterations of CaERG11 affect both the enzymic activity and the affinity for azoles of the protein. This dual effect is in fact expected since azoles bind to the active site of 14DM (Hitchcock et al., 1990; Hitchcock, 1993; Vanden Bossche \& Koymans, 1998; Vanden Bossche \& Marichal, 1992; Yoshida \& Aoyama, 1985). In contrast, strain NFI 2021, while resistant to fluconazole, incorporated $\left[1,2-{ }^{14} \mathrm{C}\right]$ acetate in a manner similar to fluconazole-sensitive stains, both qualitatively and quantitatively (Table 3 ).

\section{Amino acid substitutions in CaERG11 from the four selected azole-resistant strains}

In order to identify the molecular basis for the azole insensitivity of $14 \mathrm{DM}$ from the four selected azoleresistant isolates, we proceeded to clone and completely sequence their CaERG11 genes. As a control, we also sequenced CaERG11 cloned from the sensitive strain NFI 0124. All of the sequences contained at least one cryptic nucleotide variation (not affecting the protein sequence; data not shown) when compared to the published sequence of CaERG11 (Lai \& Kirsch, 1989). In addition, all CaERG11 genes from the azole-resistant strains contained two to four additional variations leading to amino acid substitutions in the protein sequence (Table 4). No variation leading to amino acid substitutions was found in NFI 0124 CaERG11. Since PCR amplification could lead to the introduction of random mutations and cloning of PCR products can fortuitously select the mutated sequences, CaERG11 from all five strains was PCR-amplified a second time from genomic DNA and the sequences directly determined without prior cloning. Exactly the same variations as shown in Table 4 were again found, indicating that they were not artificially introduced during the PCR amplification.

\section{Expression of CaERG11 with amino acid substitutions in S. cerevisiae confers resistance to fluconazole}

To formally demonstrate that the identified amino acid substitutions in CaERG11 from fluconazole-resistant strains could confer resistance to the antimycotic in an intact yeast cell, CaERG11 genes from fluconazoleresistant and -sensitive clinical isolates were expressed in $S$. cerevisiae. It has been shown that C. albicans $14 \mathrm{DM}$ is active when expressed in S. cerevisiae (Sanglard et al., 1998; Shyadehi et al., 1996), and 14DM from C. albicans and $S$. cerevisiae exhibit similar affinities for several azoles (Hitchcock et al., 1989, 1990; Vanden Bossche \& Marichal, 1992; Yoshida \& Aoyama, 1985). Therefore, normal expression of CaERG11 from a fluconazole-sensitive isolate in an $\operatorname{erg} 11^{+} \mathrm{S}$. cerevisiae strain should not dramatically affect the susceptibility of the cells to fluconazole. To avoid overexpression of CaERG11, which could have led to a resistant phenotype (Doignon et al., 1993; Kalb et al., 1986) and affected membrane biogenesis (Vergeres et al., 1993; Zimmer et al., 1997), we put the expression of the gene under the control of the ERG11 promoter ( -1036 to -3 ; see Methods). To monitor the expression of C. albicans $14 \mathrm{DM}$ in $S$. cerevisiae we introduced a c-myc tag (30 nucleotides long, encoding the decapeptide EQKLISEEDL) into its sequence. The CaERG11 ORFs from NFI 0124 and Darlington were initially tagged either at the $5^{\prime}$ end or at the $3^{\prime}$ end. These tagged genes were then 
Table 4. Nucleotide variations leading to amino acid substitutions identified in CaERG11 cloned from the four selected azole-resistant isolates in comparison with the sequence from sensitive strains SC5314 (Lai \& Kirsch, 1989) and NFI 0124

\begin{tabular}{|c|c|c|c|c|c|}
\hline \multirow[t]{2}{*}{ Strain } & \multirow{2}{*}{$\begin{array}{l}\text { Amino acid } \\
\text { substit. }\end{array}$} & \multicolumn{2}{|c|}{ DNA sequence* } & \multicolumn{2}{|c|}{ Protein sequence } \\
\hline & & $\begin{array}{l}\text { Fluconazole- } \\
\text { sensitive }\end{array}$ & $\begin{array}{l}\text { Fluconazole- } \\
\text { resistant }\end{array}$ & $\begin{array}{l}\text { Fluconazole- } \\
\text { sensitive }\end{array}$ & $\begin{array}{l}\text { Fluconazole- } \\
\text { resistant }\end{array}$ \\
\hline \multirow[t]{3}{*}{ Darlington } & 1 & ${ }^{214} \mathrm{TTC}$ & СТC & $P h e^{72}$ & Leu \\
\hline & 2 & ${ }^{394} \mathrm{TAT}$ & CAT & $\operatorname{Tyr}^{132}$ & His \\
\hline & 3 & ${ }^{1348} \mathrm{GGG}$ & GAG & Gly ${ }^{450}$ & Glu \\
\hline \multirow[t]{4}{*}{ NFI 2007} & 1 & ${ }^{375} \mathrm{TTC}$ & TTA & $P h e^{126}$ & Leu \\
\hline & 2 & ${ }^{796} \mathrm{GAA}$ & GAC & Glu $^{266}$ & Asp \\
\hline & 3 & ${ }^{1213} \mathrm{TCT}$ & TTT & Ser ${ }^{405}$ & Phe \\
\hline & 4 & ${ }^{1309} \mathrm{GTT}$ & ATT & $\mathrm{Val}^{437}$ & Ile \\
\hline \multirow[t]{3}{*}{ NFI 2013} & 1 & ${ }^{346} \mathrm{GAT}$ & GAA & $\mathrm{Asp}^{116}$ & Glu \\
\hline & 2 & ${ }^{394} \mathrm{TAT}$ & CAT & $\mathrm{Tyr}^{132}$ & His \\
\hline & 3 & ${ }^{1345} \mathrm{TTT}$ & CTT & $P h e^{449}$ & Leu \\
\hline \multirow[t]{2}{*}{ NFI 2021} & 1 & ${ }^{427} \mathrm{AAA}$ & GAA & Lys $^{143}$ & Glu \\
\hline & 2 & ${ }^{685} \mathrm{ACC}$ & GCC & $\mathrm{Thr}^{229}$ & Ala \\
\hline
\end{tabular}

* Nucleotides are numbered from the translation start codon ${ }^{1}$ ATG of CaERG11 ORF (Lai \& Kirsch, 1989).

Table 5. Increased resistance to fluconazole and ketoconazole in S. cerevisiae strain INVSC2 transformed with CaERG11 genes cloned from azole-resistant strains

\begin{tabular}{|c|c|c|c|c|}
\hline \multirow{2}{*}{$\begin{array}{l}\text { Transformants expressing } \\
\text { CaERG } 11 \text { from }\end{array}$} & \multirow{2}{*}{$\begin{array}{l}\text { Position of } \\
\text { c-myc tag }\end{array}$} & \multirow{2}{*}{$\begin{array}{l}\text { Expression of } \\
\text { residue } 263 \text { as }\end{array}$} & \multicolumn{2}{|c|}{$\operatorname{MIC}\left(\mu \mathrm{g} \mathrm{ml}^{-1}\right)^{*}$} \\
\hline & & & Fluconazole & Ketoconazole \\
\hline Untransformed & - & - & 64 & 2 \\
\hline Vector alone & - & - & 64 & 2 \\
\hline NFI 0124 & $\mathrm{~N}$ & Leu & 128 & 4 \\
\hline NFI 0124 & $\mathrm{C}$ & Leu & 256 & 8 \\
\hline NFI 0124 & $\mathrm{C}$ & Ser & 128 & 4 \\
\hline Darlington & $\mathrm{N}$ & Leu & 1024 & 32 \\
\hline Darlington & $\mathrm{C}$ & Leu & 4096 & 64 \\
\hline Darlington & $\mathrm{C}$ & Ser & 4096 & 64 \\
\hline NFI 2007 & $\mathrm{C}$ & Ser & 4096 & 16 \\
\hline NFI 2021 & $\mathrm{C}$ & Ser & 4096 & 16 \\
\hline
\end{tabular}

*Values obtained in two or three out of three independent determinations. Variations did not exceed a twofold dilution step.

cloned into the centromere vector pRS416 in between the ERG11 promoter and the terminator of $S$. cerevisiae CYC1.

S. cerevisiae INVSC2 was transformed with the vector containing CaERG11, or with vector alone, and then tested for susceptibility to fluconazole and ketoconazole (this strain was primarily resistant to itraconazole) (Table 5). Expression of CaERG11 from the Darlington strain conferred an increased resistance to fluconazole in comparison with that from NFI 0124. However, the position of the c-myc tag influenced the susceptibility of the transformants to both fluconazole and ketoconazole whatever the source of CaERG11 (Table 5). Western blotting with anti-c-myc tag antibody revealed that this variation in susceptibility correlated with the apparent level of expression of 14DM. Proteins tagged at the carboxyl (C) terminus were more abundant than those tagged at the amino $(\mathrm{N})$ terminus (Fig. 1; compare lanes 2-7 with lanes 8 and 9). The c-myc tag at the $\mathrm{N}$-terminus might interfere with the targeting of $14 \mathrm{DM}$ to the membrane of the endoplasmic reticulum, which depends on a transmembrane domain and also probably on clusters of positively charged residues, both situated toward the N-terminus of $\mathrm{P} 450$ proteins (Boscott \& Grant, 1994; Chen et al., 1988; Sanglard et al., 1993). CaERG11 from NFI 2007 and NFI 2021 were therefore exclusively tagged at the C-terminus. A cryptic alter- 


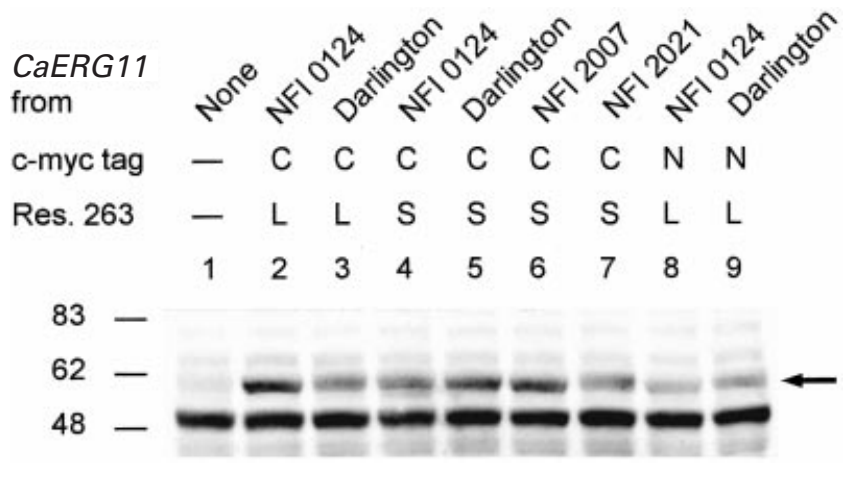

Fig. 1. Western blot analysis of the expression of c-myc-tagged CaERG11 from whole homogenates $(30 \mu \mathrm{g}$ protein) of $\mathrm{S}$. cerevisiae INVSC2 transformed with the vector or plasmid containing CaERG11 cloned from several C. albicans strains with anti-c-myc tag antibodies (see Methods for details). The strain from which CaERG11 was derived, the position [amino (N) or carboxyl (C)] of the c-myc tag, and the designated amino acid residue at position 263 in the expressed protein are indicated above the Western blot. Molecular mass markers $(\mathrm{kDa})$ are shown on the left. The band corresponding to c-myc-tagged $C$. albicans 14DM is arrowed. The results are representative of two independent experiments.

ation of NFI 2013 CaERG11 introduced an XbaI site at position 409 of the ORF (data not shown), precluding its cloning into the expression vector, which was based on a strategy involving two digestions with $\mathrm{XbaI}$. Since codon CUG is decoded as Ser in C. albicans instead of Leu (Santos \& Tuite, 1995), expression of CaERG11 in $S$. cerevisiae introduces the substitution S263L. To ensure that this would not influence the sensitivity of $14 \mathrm{DM}$ to inhibitors, the triplet ${ }^{787} \mathrm{CTG}$ was systematically replaced by TCT (a Ser codon) in CaERG11 tagged at the $3^{\prime}$ end. Results obtained with these last plasmids are presented in Table 5. The substitution S263L in CaERG11 gene from the sensitive strain NFI 0124 resulted in a slight decrease (one step dilution) in fluconazole and ketoconazole resistance. Transformants expressing the CaERG11 genes from fluconazole-resistant strains were 32-fold more resistant to fluconazole than transformants expressing CaERG11 from the sensitive strain (Table 5). The identity of residue 263, Ser or Leu, did not affect MICs to fluconazole of transformants expressing the CaERG11 genes from resistant strains (data not shown). The amino acid substitutions present in the Darlington CaER G11 gene simultaneously conferred a potent cross-resistance to ketoconazole (16fold more than the control), in the other cases crossresistance to ketoconazole was weak (4-fold) (Table 5). Transformants expressing NFI 2007 CaERG11 without the amino acid substitution E266D were indistinguishable from those expressing CaERG11 containing all four amino acid substitutions identified in this gene (not shown).

Western blot analysis of extracts from transformants with anti-c-myc antibodies showed that 14DM from fluconazole-sensitive or -resistant C. albicans strains were equally abundant, ruling out that increased ex- pression or stability of altered proteins could account for increased MICs (Fig. 1).

\section{DISCUSSION}

In this study we have demonstrated for three C. albicans clinical isolates that lower susceptibility to fluconazole could be at least partly due to the presence of amino acid substitutions in CaERG11, since expression of the altered genes in $S$. cerevisiae led to a resistant phenotype when compared to transformants expressing CaERG11 from a sensitive strain. In all three cases altered sensitivity of sterol synthesis to fluconazole in cell-free lysates was a good screening tool to identify altered CaERG11, which can confer fluconazole resistance upon a yeast cell. Therefore, it is most probable that the amino acid substitutions identified in NFI 2013 CaERG11, and that detected by White (1997b), R467K, are in the same way responsible for the observed biochemical insensitivity to fluconazole, and contribute to the overall fluconazole resistance of these strains. However, it remains to be investigated whether underor overexpression of NADPH P450 reductase or cytochrome $b_{5}$ reductase, which alters the susceptibility of $S$. cerevisiae to azoles (Sutter \& Loper, 1989; Truan et al., 1994), has a similar effect on the affinity of 14DM for azoles in C. albicans cell extracts, and whether this mode of resistance occurs in Candida isolates. It cannot therefore be concluded without reserve that lower sensitivity of sterol synthesis to azoles in cell-free extracts is invariably associated with mutation(s) of CaERG11.

Sixteen different mutations leading to amino acid substitutions have previously been identified in CaERG11 from fluconazole-resistant isolates (Loeffler et al., 1997; Sanglard et al., 1998; White, 1997b). We report here five new, previously undescribed substitutions, to give a total of 21 which are now known. This multiplicity of mutations in CaERG11 potentially leading to fluconazole resistance, and their widespread distribution along the primary structure, might be surprising at first glance. However, a molecular model for C. albicans $14 \mathrm{DM}$ has been derived from the crystallographic structure of bacterial (Pseudomonas putida) soluble P450 camphor hydroxylase (P450cam) (Boscott \& Grant, 1994; Poulos et al., 1987) (see also Loeffler et al., 1997; Sanglard et al., 1998). The active site of P450 proteins is buried in the core of the protein and is constituted by a complex three-dimensional arrangement of various secondary structures involving several parts of the linear protein sequence. It is thus not surprising that several amino acid substitutions along the primary structure of $14 \mathrm{DM}$ can affect the affinity of azoles, which act as competitive inhibitors by binding to the active site.

Fourteen of these 21 known amino acid substitutions involve residues which are conserved in all the yeast 14DM genes which have been sequenced so far. Six of these are located in a segment spanning residues 126-147, three are clustered at positions 448-450, and 


\begin{tabular}{|c|c|c|c|c|c|c|}
\hline & $Y E F \underline{L}$ & - & ${ }^{2} \times=$ & & & \\
\hline C.g. & PYEFĒE & PV $\overline{\mathbf{F}} G \overline{\mathbf{K}} G V I \overline{\mathbf{Y}} D$ & $E Q \overline{\mathbf{K}} K F \overline{\mathrm{K}} \mathrm{G}$ & KGFT PI & 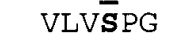 & 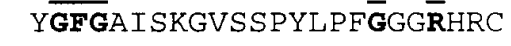 \\
\hline.$c$ & PYEFFE & PVFGKGVIYD & EQKKFVKG & KGFTPI & VLVSPG & YGFGAISKGVSSPYLPFGGGRHRC \\
\hline.$t$ & PYEFFE & PVFGKGVIYD & EQKKFAKF & KGFTPI & VI & YGFGKISKG \\
\hline$k$. & PYEFFE & PVFGKGVIYD & QKKFAKV & GFTPL & ?G & YGFGKISKG \\
\hline . i. & PYQFFF & PVFGSDVVYD & QKKFAKY & GFSPI & SPG & YLPFGAGF \\
\hline$U . n$ & PYKFYK & PVFGRD & QKKFMKT & PI & & YGYC \\
\hline$S \cdot I$ & PYVFFR & PVFGKDV & KFIKS & & & YGYGLVT \\
\hline$n$ & PYKFFE & PVFGKEVVYD & FVKV & SGFTPI & IMAAPG & FGFGMISTGANSPYLPFGAGRHRC \\
\hline & & $\star \star \star \quad *:: *$ & & $\star \star:^{\star}:$ & & 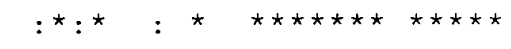 \\
\hline$\mu$ & QFLE & PVFGKGVAYD & & GFSHA & & ----- PASGEKF \\
\hline ur & EFLE & KGVAYD & MLKS & $\mathrm{HA}$ & VC & $-\ldots-$ PA \\
\hline & & $\star \star$ & & & & \\
\hline
\end{tabular}

Fig. 2. Comparison of fungal and mammalian 14DM protein sequences surrounding amino acid substitutions identified in CaERG11 from fluconazole-resistant strains (in bold and underlined), and involving conserved residues in most fungal 14DM sequences (in bold). Alignment was performed with the CLUSTAL W (1.74) program (Thompson et al., 1994). Asterisks show conserved residues, colons indicate conserved replacements, and hyphens correspond to gaps. The accession numbers are, from top to bottom: C. albicans, X13296; C. glabrata, S75389; S. cerevisiae, M18109; C. tropicalis, M23673; C. krusei, S75391; Penicillium italicum, Z49750; Uncinula necator, U83840; Schizosaccharomyces pombe, Q09736; Ustilago maydis, Z48164; rat, D55681; human, D55653.

two are in the proximity of the thiolate (5th) ligand of the haem $\left(\mathrm{Cys}^{470}\right)$ (Fig. 2). Amino acid substitutions from position 126 to 147 are close to or part of the entrance port for the substrate leading to the active site. For instance, Lys ${ }^{143}$, substituted by Glu in CaERG11 from isolate NFI 2021, is thought to be important for membrane binding and the correct entrance of the substrate (Boscott \& Grant, 1994; Loeffler et al., 1997). Amino acid substitutions between residues 405 to 450 are located in the 'helix-poor' domain connecting helices $\mathrm{K}$ to $\mathrm{L}$, which are involved in the substratebinding site in P450cam (Boscott \& Grant, 1994; Poulos et al., 1987). Surprisingly, despite the selectivity of fluconazole for fungal versus mammalian 14DM, 10 out of the 14 residues substituted in CaERG11 from azoleresistant isolates are conserved in both fungal and mammalian 14DMs (Fig. 2).

The occurrence of two or more amino acid substitutions appears to be common in CaERG11 from fluconazoleresistant strains (Loeffler et al. 1997; Sanglard et al. 1998 ; our work). It is unclear as yet whether all identified mutations are important for conferring reduced affinity for azoles. For instance, substitution E266D found in CaERG11 from NFI 2007 and four fluconazole-resistant isolates by Loeffler et al. (1997) seems to be irrelevant in CaERG11 from NFI 2007 for conferring resistance to either fluconazole or ketoconazole. Sanglard et al. (1998) found by introducing some amino acid substitutions in CaERG11 from a sensitive strain that double point mutations usually have a synergistic effect over single amino acid substitution, explaining the apparent natural occurrence of more than one mutation in azole-resistant CaERG11. S. cerevisiae transformants expressing CaERG11 from strains Darlington, NFI 2007 or NFI 2021 were up to 32-fold more resistant to fluconazole than those expressing CaERG11 from a fluconazolesensitive strain. Moreover, at the high concentration of $4096 \mu \mathrm{g} \mathrm{m}^{-1}(13 \mathrm{mM})$, fluconazole might exert non- specific toxicity so that the real extent of resistance induced by mutations in CaERG11 might well be higher than 32-fold.

Mutations in CaERG11 from strains Darlington, NFI 2007 and NFI 2013 negatively affected not only the affinity for azoles but also the enzymic activity (Table 2), as expected from the competitive inhibition of 14DM by azoles. Therefore, the apparent lack of effect on 14DM activity of the new amino acid substitutions identified in CaERG11 from NFI 2021, K143E and T229A is intriguing, although a similar phenomenon has been suggested to occur in azole-resistant Ustilago maydis strains (Joseph-Horne et al., 1995). It is conceivable that these mutations somehow affect the binding of fluconazole without influencing enzyme activity, since there was no indication of any abnormal accumulation of ergosterol pathway intermediates in NFI 2021 (Table 3). An alternative explanation is that reduced substrate binding of 14DM is compensated by an up-regulation of $14 \mathrm{DM}$ and possibly other enzymes in the pathway. In support of the latter explanation, evidence has been found for overexpression of both 14DM and squalene epoxidase in this strain (authors' unpublished data), which would be compatible with the normal profile seen in Table 3. The lack of marked cross-resistance to itraconazole and ketoconazole in NFI 2021, together with the similar extent of reduction in sensitivity to azoles in the cell-free and whole-cell ergosterol biosynthesis assays (Table 2), suggests that resistance in this strain may be accounted for solely by these changes in the ergosterol pathway.

Amino acid substitutions in CaERG11 probably do not constitute the sole mechanism of resistance to antimycotics present in any of the four strains examined. In contrast to NFI 2021 discussed above, strains Darlington, NFI 2007 and NFI 2013 show cross-resistance to other azoles and a more marked reduction of sensitivity of ergosterol biosynthesis in whole cells than in cell-free 
assays (Table 2). For example, NFI 2013 is strongly resistant to itraconazole but its sterol synthesis in cellfree extracts is very sensitive to the same azole. Therefore, these three strains probably also express one or more transporters which reduce the intracellular concentration of the antimycotics. In support of this, reduced cellular accumulation of fluconazole was observed in strains Darlington, NFI 2007 and NFI 2013, but not in NFI 2021 (authors' unpublished data). A similar diversity of resistance mechanisms expressed in a single isolate has previously been observed (Lopez-Ribot et al., 1998; Sanglard et al., 1998; White, 1997a).

In conclusion, azole resistance in C. albicans is a complex phenomenon which can involve several different mechanisms. In addition to overexpression of the target enzyme or drug transporters, which have been widely reported, mutations in CaERG11 can significantly contribute to a clinically occurring resistant phenotype induced by long-term treatment of patients with azoles. Our data suggest that amino acid substitutions in $14 \mathrm{DM}$ may contribute to resistance in about $20 \%$ of fluconazole-resistant C. albicans strains. The diversity of the mutations able to influence the affinity of 14DM for azoles precludes any simple analysis to detect them. Moreover, selection of more than one resistance mechanism by prolonged treatment with azoles also seems to be very common (Lopez-Ribot et al., 1998; Sanglard et al., 1998; White, 1997a), excluding a simple therapeutic approach to combat azole resistance. Combination of antimycotics with different modes of action, for example azole and allylamine (Barchiesi et al., 1998; Ryder \& Favre, 1997), is one potential approach to this problem.

\section{ACKNOWLEDGEMENTS}

We thank B. F. Dupont (Paris), A. G. Georgopoulos (Vienna), D. Marriott (Sydney), P. Regli (Marseille) and M. G. Rinaldi (San Antonio) for supplying clinical isolates, I. Leitner for performing MIC determinations, and W. Mlineritsch for sterol biosynthesis assays. We also thank Karl Kleine for critical reading of the manuscript. This work was presented in part at the 37th Interscience Conference on Antimicrobial Agents and Chemotherapy, Toronto, 1997 (Abstract C-13, American Society for Microbiology).

\section{REFERENCES}

Alarco, A. M., Balan, I., Talibi, D., Mainville, N. \& Raymond, M. (1997). AP1-mediated multidrug resistance in Saccharomyces cerevisiae requires FLR1, encoding a transporter of the major facilitator superfamily. J Biol Chem 272, 19304-19313.

Albertson, G. D., Niimi, M., Cannon, R. D. \& Jenkinson, H. F. (1996). Multiple efflux mechanisms are involved in Candida albicans fluconazole resistance. Antimicrob Agents Chemother 40, 2835-2841.

Aoyama, Y., Yoshida, Y., Sonoda, Y. \& Sato, Y. (1989). Deformylation of 32-oxo-24,25-dihydrolanosterol by the purified cytochrome P-450 ${ }_{14 \mathrm{DM}}$ (lanosterol $14 \alpha$-demethylase) from yeast, evidence confirming the intermediate step of lanosterol $14 \alpha$ demethylase. J Biol Chem 264, 18502-18505.

Barchiesi, F., Difrancesco, L. F., Compagnucci, P., Arzeni, D.,
Giacometti, A. \& Scalise, G. (1998). In-vitro interaction of terbinafine with amphotericin $\mathrm{B}$, fluconazole and itraconazole against clinical isolates of Candida albicans. J Antimicrob Chemother 41, 59-65.

Becker, D. M. \& Guarente, L. (1991). High-efficiency transformation of yeast by electroporation. Methods Enzymol 194, 182-187.

Boscott, P. E. \& Grant, G. H. (1994). Modeling cytochrome P450 14 $\alpha$-demethylase (Candida albicans) from P450cam. J Mol Graphics 12, 185-192.

Chen, C., Kalb, V. F., Turi, T. G. \& Loper, J. C. (1988). Primary structure of the cytochrome P450 lanosterol 14 $\alpha$-demethylase gene from Candida tropicalis. DNA 7, 617-626.

Denning, D. W., Baily, G. G. \& Hood, S. V. (1997). Azole resistance in Candida. Eur J Clin Microbiol Infect Dis 16, 261-280.

Doignon, F., Aigle, M. \& Ribereaugayon, P. (1993). Resistance to imidazoles and triazoles in Saccharomyces cerevisiae as a new dominant marker. Plasmid 30, 224-233.

Favre, B. \& Ryder, N. S. (1996). Characterization of squalene epoxidase activity from the dermatophyte Trichophyton rubrum and its inhibition by terbinafine and other antimycotic agents. Antimicrob Agents Chemother 40, 443-447.

Favre, B. \& Ryder, N. S. (1997a). Cloning and expression of squalene epoxidase from the pathogenic yeast Candida albicans. Gene 189, 119-126.

Favre, B. \& Ryder, N. S. (1997b). Differential inhibition of fungal and mammalian squalene epoxidases by the benzylamine SDZ SBA 586 in comparison with the allylamine terbinafine. Arch Biochem Biophys 340, 265-269.

Feczcko, J. M. (1992). 17. Overview of fluconazole. In Recent Progress in Antifungal Therapy, pp. 191-201. Edited by $\mathrm{H}$. Yamaguchi, G. S. Kobayashi \& H. Takahashi. New York: Marcel Dekker.

Galgiani, J. N., Bartlett, M. S., Ghannoum, M. A., Espinell-Ingroff, A., Lancaster, M. V., Odds, F. C., Pfaller, M. A., Rex, J. H. \& Rinaldi, M. G. (1995). Reference Method for Broth Dilution Antifungal Susceptibility Testing of Yeasts; Tentative Standard. Wayne, PA: NCCLS.

Ghannoum, M. A., Rex, J. H. \& Galgiani, J. N. (1996). Susceptibility testing of fungi: current status of correlation of in vitro data with clinical outcome. J Clin Microbiol 34, 489-495.

Goldway, M., Teff, D., Schmidt, R., Oppenheim, A. B. \& Koltin, Y. (1995). Multidrug resistance in Candida albicans: disruption of the $B E N^{r}$ gene. Antimicrob Agents Chemother 39, 422-426.

Hitchcock, C. A. (1993). 15. Chemistry and mode of action of fluconazole. In Cutaneous Antifungal Agents. Selected Compounds in Clinical Practice and Development, pp. 183-197. Edited by J. W. Rippon \& R. A. Fromtling. New York: Marcel Dekker.

Hitchcock, C. A., Dickinson, K., Brown, S. B., Evans, E. G. V. \& Adams, D. J. (1989). Purification and properties of cytochrome P450-dependent $14 \alpha$-sterol demethylase from Candida albicans. Biochem J 263, 573-579.

Hitchcock, C. A., Dickinson, K., Brown, S. B., Evans, E. G. V. \& Adams, D. J. (1990). Interaction of azole antifungal antibiotics with cytochrome P-450-dependent $14 \alpha$-sterol demethylase purified from Candida albicans. Biochem J 266, 475-480.

Ishida, N., Aoyama, Y., Hatanaka, R. \& 10 other authors (1988). A single amino acid substitution converts cytochrome $\mathrm{P} 450_{14 \mathrm{DM}}$ to an inactive form, cytochrome $\mathrm{P}^{450_{\mathrm{SG} 1}}$ : complete primary structures deduced from cloned DNAs. Biochem Biophys Res Commun $155,317-323$.

Joseph-Horne, T., Hollomon, D., Loeffler, R. S. T. \& Kelly, S. L. 
(1995). Altered P450 activity associated with direct selection for fungal azole resistance. FEBS Lett 374, 174-178.

Kalb, V. F., Loper, J. C., Dey, C. R., Woods, C. W. \& Sutter, T. R. (1986). Isolation of a cytochrome P-450 structural gene from Saccharomyces cerevisiae. Gene 45, 237-245.

Kelly, S. L., Arnoldi, A. \& Kelly, D. E. (1993). Molecular genetic analysis of azole antifungal mode of action. Biochem Soc Trans 21, 1034-1038.

Kelly, S. L., Lamb, D. C., Kelly, D. E., Manning, N. J., Loeffler, J., Hebart, H., Schumacher, U. \& Einsele, H. (1997). Resistance to fluconazole and cross-resistance to amphotericin B in Candida albicans from AIDS patients caused by defective sterol $\Delta(5,6)$ desaturation. FEBS Lett 400, 80-82.

Lai, M. H. \& Kirsch, D. R. (1989). Nucleotide sequence of cytochrome P450 L1A1 (lanosterol 14 $\alpha$-demethylase) from Candida albicans. Nucleic Acids Res 17, 804.

Lamb, D. C., Corran, A., Baldwin, B. C., Kwonchung, J. \& Kelly, S. L. (1995). Resistant P45051A1 activity in azole antifungal tolerant Cryptococcus neoformans from AIDS patients. FEBS Lett 368, 326-330.

Lamb, D. C., Kelly, D. E., Schunck, W. H., Shyadehi, A. Z., Akhtar, M., Lowe, D. J., Baldwin, B. C. \& Kelly, S. L. (1997). The mutation T315A in Candida albicans sterol $14 \alpha$-demethylase causes reduced enzyme activity and fluconazole resistance through reduced affinity. J Biol Chem 272, 5682-5688.

Law, D., Moore, C. B., Wardle, H. M., Ganguli, L. A., Keaney, M. G. L. \& Denning, D. W. (1994). High prevalence of antifungal resistance in Candida spp. from patients with AIDS. J Antimicrob Chemother 34, 659-668.

Loeffler, J., Kelly, S. L., Hebart, H., Schumacher, U., Lassflorl, C. \& Einsele, H. (1997). Molecular analysis of cyp51 from fluconazoleresistant Candida albicans strains. FEMS Microbiol Lett 151, 263-268.

Lopez-Ribot, J. L., Mcatee, R. K., Lee, L. N., Kirkpatrick, W. R., White, T. C., Sanglard, D. \& Patterson, T. F. (1998). Distinct patterns of gene expression associated with development of fluconazole resistance in serial Candida albicans isolates from human immunodeficiency virus-infected patients with oropharyngeal candidiasis. Antimicrob Agents Chemother 42, 2932-2937.

Marichal, P., Gorrens, J., Coene, M. C., Lejeune, L. \& Vandenbossche, H. (1995). Origin of differences in susceptibility of Candida krusei to azole antifungal agents. Mycoses 38, 111-117.

Miyazaki, H., Miyazaki, Y., Geber, A., Parkinson, T., Hitchcock, C., Falconer, D. J., Ward, D. J., Marsden, K. \& Bennett, J. E. (1998). Fluconazole resistance associated with drug efflux and increased transcription of a drug transporter gene, PDH1, in Candida glabrata. Antimicrob Agents Chemother 42, 1695-1701.

Moran, G. P., Sanglard, D., Donnelly, S. M., Shanley, D. B., Sullivan, D. J. \& Coleman, D. C. (1998). Identification and expression of multidrug transporters responsible for fluconazole resistance in Candida dubliniensis. Antimicrob Agents Chemother 42, 1819-1830.

Orozco, A. S., Higginbotham, L. M., Hitchcock, C. A., Parkinson, T., Falconer, D., Ibrahim, A. S., Ghannoum, M. A. \& Filler, S. G. (1998). Mechanism of fluconazole resistance in Candida krusei. Antimicrob Agents Chemother 42, 2645-2649.

Parkinson, T., Falconer, D. J. \& Hitchcock, C. A. (1995). Fluconazole resistance due to energy-dependent drug efflux in Candida glabrata. Antimicrob Agents Chemother 39, 1696-1699.

Philippsen, P., Stotz, A. \& Scherf, C. (1991). DNA of Saccharomyces cerevisiae. Methods Enzymol 194, 169-182.
Poulos, T. L., Finzel, B. C. \& Howard, A. J. (1987). High-resolution crystal structure of cytochrome P450cam. J Mol Biol 195, 687-700.

Prasad, R., Dewergifosse, P., Goffeau, A. \& Balzi, E. (1995). Molecular cloning and characterization of a novel gene of Candida albicans, CDR1, conferring multiple resistance to drugs and antifungals. Curr Genet 27, 320-329.

Rex, J. H., Rinaldi, M. G. \& Pfaller, M. A. (1995). Resistance of Candida species to fluconazole. Antimicrob Agents Chemother 39, 1-8.

Rex, J. H., Pfaller, M. A., Lancaster, M., Odds, F. C., Bolmstrom, A. \& Rinaldi, M. G. (1996). Quality control guidelines for National Committee for clinical laboratory standards-recommended broth macrodilution testing of ketoconazole and itraconazole. $J$ Clin Microbiol 34, 816-817.

Rinaldi, M. G. (1993). 1. Biology and pathogenicity of Candida species. In Candidiasis. Pathogenesis, Diagnosis, and Treatment, pp. 1-20. Edited by G. P. Bodey. New York: Raven Press.

Ryder, N. S. (1985). Specific inhibition of fungal sterol biosynthesis by SF 86-327, a new allylamine antimycotic agent. Antimicrob Agents Chemother 27, 252-256.

Ryder, N. S. (1987). Squalene epoxidase as the target of antifungal allylamines. Pestic Sci 21, 281-288.

Ryder, N. S. \& Favre, B. (1997). Antifungal activity and mechanism of action of terbinafine. Rev Contemp Pharmacother 8, 275-287.

Ryder, N. S., Seidl, G. \& Troke, P. F. (1984). Effect of the antimycotic drug naftifine on growth of and sterol biosynthesis in Candida albicans. Antimicrob Agents Chemother 25, 483-487.

Ryder, N. S., Wagner, S. \& Leitner, I. (1998). In vitro activities of terbinafine against cutaneous isolates of Candida albicans and other pathogenic yeasts. Antimicrob Agents Chemother 42, 1057-1061.

Ryley, J. F., Wilson, R. G. \& Barrett-Bee, K. J. (1984). Azole resistance in Candida albicans. Sabouraudia 22, 53-63.

Sanglard, D., Sengstag, C. \& Seghezzi, W. (1993). Probing the membrane topology of Candida tropicalis cytochrome P450. Eur J Biochem 216, 477-485.

Sanglard, D., Kuchler, K., Ischer, F., Pagani, J. L., Monod, M. \& Bille, J. (1995). Mechanisms of resistance to azole antifungal agents in Candida albicans isolates from AIDS patients involve specific multidrug transporters. Antimicrob Agents Chemother 39, 2378-2386.

Sanglard, D., Ischer, F., Monod, M. \& Bille, J. (1996). Susceptibilities of Candida albicans multidrug transporter mutants to various antifungal agents and other metabolic inhibitors. Antimicrob Agents Chemother 40, 2300-2305.

Sanglard, D., Ischer, F., Monod, M. \& Bille, J. (1997). Cloning of Candida albicans genes conferring resistance to azole antifungal agents: characterization of CDR2, a new multidrug ABC transporter gene. Microbiology 143, 405-416.

Sanglard, D., Ischer, F., Koymans, L. \& Bille, J. (1998). Amino acid substitutions in the cytochrome P-450 lanosterol 14 alphademethylase (CYP51A1) from azole-resistant Candida albicans clinical isolates contribute to resistance to azole antifungal agents. Antimicrob Agents Chemother 42, 241-253.

Santos, M. A. S. \& Tuite, M. F. (1995). The CUG codon is decoded in vivo as serine and not leucine in Candida albicans. Nucleic Acids Res 23, 1481-1486.

Shyadehi, A. Z., Lamb, D. C., Kelly, S. L., Kelly, D. E., Schunck, W. H., Wright, J. N., Corina, D. \& Akhtar, M. (1996). The mechanism of the acyl-carbon bond cleavage reaction catalyzed by recombinant sterol $14 \alpha$-demethylase of Candida albicans 
(other names are: lanosterol 14 $\alpha$-demethylase, P-450(14DM), and CYP51). J Biol Chem 271, 12445-12450.

Sutter, T. R. \& Loper, J. C. (1989). Disruption of Saccharomyces cerevisiae gene for NADPH-cytochrome P450 reductase causes increased sensitivity to ketoconazole. Biochem Biophys Res Commun 160, 1257-1266.

Thompson, J. D., Higgins, D. G. \& Gibson, T. J. (1994). CLUSTAL w : improving the sensitivity of progressive multiple sequence alignment through sequence weighting, position-specific gap penalties and weight matrix choice. Nucleic Acids Res 22, 4673-4680.

Truan, G., Epinat, J. C., Rougeulle, C., Cullin, C. \& Pompon, D. (1994). Cloning and characterization of a yeast cytochrome $b_{5}$ encoding gene which suppresses ketoconazole hypersensitivity in a NADPH-P-450 reductase-deficient strain. Gene 142, 123-127.

Tumbarello, M., Caldarola, G., Tacconelli, E., Morace, G., Posteraro, B., Cauda, R. \& Ortona, L. (1996). Analysis of the risk factors associated with the emergence of azole resistant oral candidosis in the course of HIV infection. J Antimicrob Chemother 38, 691-699.

Vanden Bossche, H. \& Koymans, L. (1998). Cytochromes P450 in fungi. Mycoses 41, Suppl. 1, 32-38.

Vanden Bossche, H. \& Marichal, P. (1992). 3. Azole antifungals: mode of action. In Recent Progress in Antifungal Chemotherapy, pp. 25-40. Edited by H. Yamaguchi, G. S. Kobayashi \& H. Takahashi. New York: Marcel Dekker.

Vanden Bossche, H., Marichal, P., Gorrens, J., Bellens, D., Moereels, H. \& Janssen, P. A. J. (1990). Mutation in cytochrome P-450-dependent $14 \alpha$-demethylase results in decreased affinity for azole antifungals. Biochem Soc Trans 18, 56-59.

Vanden Bossche, H., Marichal, P., Odds, F. C., Le Jeune, L. \& Coene, M. C. (1992). Characterization of an azole-resistant Candida glabrata isolate. Antimicrob Agents Chemother 36, 2602-2610.

Vanden Bossche, H., Marichal, P. \& Odds, F. C. (1994). Molecular mechanisms of drug resistance in fungi. Trends Microbiol 2, 393-400.

van Veen, H. W. \& Konings, W. N. (1998). The ABC family of multidrug transporters in microorganisms. Biochim Biophys Acta 1365, 31-36.

Venkateswarlu, K., Denning, D. W., Manning, N. J. \& Kelly, S. L. (1996). Reduced accumulation of drug in Candida krusei accounts for itraconazole resistance. Antimicrob Agents Chemother 40, 2443-2446.

Venkateswarlu, K., Taylor, M., Manning, N. J., Rinaldi, M. G. \& Kelly, S. L. (1997). Fluconazole tolerance in clinical isolates of Cryptococcus neoformans. Antimicrob Agents Chemother 41, 748-751.

Vergeres, G., Yen, T. S. B., Aggeler, J., Lausier, J. \& Waskell, L. (1993). A model system for studying membrane biogenesis. Overexpression of cytochrome $b_{5}$ in yeast results in marked proliferation of the intracellular membrane. J Cell Sci 106, 249-259.

White, T. C. (1997a). Increased mRNA levels of ERG16, CDR, and MDR 1 correlate with increases in azole resistance in Candida albicans isolates from a patient infected with human immunodeficiency virus. Antimicrob Agents Chemother 41, 1482-1487.

White, T. C. (1997b). The presence of an R467K amino acid substitution and loss of allelic variation correlate with an azoleresistant lanosterol $14 \alpha$ demethylase in Candida albicans. Antimicrob Agents Chemother 41, 1488-1494.

White, T. C., Marr, K. A. \& Bowden, R. A. (1998). Clinical, cellular, and molecular factors that contribute to antifungal drug resistance. Clin Microbiol Rev 11, 382-402.

Yoshida, M. \& Aoyama, Y. (1985). Interaction of azole fungicides with yeast cytochrome P-450 which catalyzes lanosterol $14 \alpha$ demethylation. In In Vitro and In Vivo Evaluation of Antifungal Agents, pp. 123-134. Edited by K. Iwata \& H. Vanden Bossche. Amsterdam: Elsevier.

Zimmer, T., Vogel, F., Ohta, A., Takagi, M. \& Schunck, W. H. (1997). Protein quality - a determinant of the intracellular fate of membrane-bound cytochromes P450 in yeast. DNA Cell Biol 16, 501-514.

Received 8 February 1999; revised 21 May 1999; accepted 28 May 1999. 